\title{
A cross sectional study of periorbital dermatoses in a tertiary care hospital in South India
}

\author{
Monisha Shetty ${ }^{1, *}$, Sowmya ${ }^{2}$ \\ ${ }^{1}$ Post Graduate, ${ }^{2} \mathrm{MD}$, Dept. of Dermatology, ${ }^{\mathbf{1 , 2}} \mathrm{AJ}$ Institute of Medical Sciences \& Research Centre, Mangaluru, Karnataka, India \\ *Corresponding Author: \\ Email: shetty.monisha@gmail.com
}

\begin{abstract}
Introduction: Periorbital dermatoses are the dermatological manifestations of the area around the eye excluding eyelid. It greatly affects quality of life. As there is lack of adequate data about frequency and distribution of periorbital dermatoses, there is need for studies to be conducted to study clinical patterns of periorbital dermatoses. Aesthetic facial concerns have been the main reason for dermatological consults in the last few years, one among which is the periorbital dermatoses.

Methodology: It was a hospital based cross sectional study of 75 patients, attending Dermatology OPD in a tertiary care hospital, with complains of periorbital dermatoses. Detailed history, general physical, and detailed cutaneous examination was done in all patients included in the study. Clinical tests, routine haematological investigations \& skin biopsy were performed in relevant cases.

Results and Discussion: Among 75 patients, common dermatological condition distributed in the periorbital region was periorbital tumors 26 patients(34.7\%), pigmentary disorders $18(24 \%)$,dermatitis $18(24 \%)$ infections $7(9.33 \%)$ and miscellaneous $6(8 \%)$. Among all seborrheic keratosis and periorbital hyperpigmentation were observed to be the commonest conditions in our study.

Conclusion: Certain periorbital dermatoses are heralding features of underlying systemic disease, so it helps in early diagnosis and treatment of underlying condition. In our study periorbital tumours were the commonest dermatoses seen.
\end{abstract}

Keywords: Dermatoses, Periorbital, Hyperpigmentation, Tumors.

\section{Introduction}

Among the various cosmetic concerns of the face, one of the most common concerns are periorbital dermatoses. Periorbital dermatoses are manifestations of the skin presenting in the area around the eye including the eyelid. These disorders pose both diagnostic and therapeutic challenge for dermatologists. ${ }^{1}$

Although they do not cause morbidity, they are of significant aesthetic concern especially for female patients and can influence the quality of life in some patients. $^{2}$

Periorbital dermatosis may serve as indicators of underlying systemic disease and help in the early diagnosis and treatment of the condition. The periocular area may present with various conditions which could either be infectious or non-infectious diseases such as inflammatory dermatoses, systemic disease, drug reactions, benign and malignant lesions, traumatic lesions, pigmentary changes and aesthetic complications. ${ }^{3}$

Adequate data about the frequency and distribution of spectrum of periorbital dermatoses in India is lacking. Hence this cross sectional study was undertaken in our institute to study the clinical spectrum of periorbital dermatoses and to assess the association of systemic diseases with periorbital dermatoses.

\section{Aims and Objectives}

To study the frequency and distribution of periorbital dermatoses of varied etiology.

\section{Materials and Methods}

This was a hospital based, cross sectional clinical study. The study group consisted of 75 patients who attended the Dermatology OPD in A $\mathbf{J}$ institute of Medical Sciences Mangalore, Karnataka from January 2018 to June 2018, with dermatological conditions pertaining to the periorbital area.

Patients with periorbital dermatosis of both genders and all ages were enrolled in the study after taking informed written consent.

A detailed history was taken followed by cutaneous and general physical examination. Complete blood counts, hemoglobin percentage, ESR, blood sugar, lipid profile, absolute eosinophil count, TSH, T3, T4, USG abdomen \& pelvis, chest $\mathrm{x}$-ray, skin biopsy were done in relevant cases.

Clinical tests Wood's lamp examination, $\mathrm{KOH}$ mount, tzanck smear, slit skin smear, gram stain and patch test were performed wherever required. Non consenting patients with periorbital dermatoses were excluded from study.

\section{Statistical Analysis}

The data was analysed using software SPSS 17.0.1. 


\section{Observations and Results}

A total of 75 patients with periorbital dermatoses were included in the study. Among the 75 patients, 42 patients were females while 33 patients were males. The most common age group found to be affected by the periorbital dermatoses was 30-50 years.

The most common periorbital dermatosis encountered in our study was periorbital tumours. Out of the 75 patients, 26 patients $(34.7 \%)$ had periorbital tumours. The next most common periorbital dermatoses are pigmentary disorders and periorbital dermatitis seen in 18 patients $(24 \%)$ each, followed by periorbital infections seen in 7 patients $(9.3 \%)$ and 6 patients $(8 \%)$ had miscellaneous periorbital dermatoses. The various periorbital dermatoses encountered are shown in Table 1.

Table 1: Various periorbital dermatoses seen

\begin{tabular}{|l|c|c|}
\hline Periorbital dermatoses & No. of Cases & Percentage \\
\hline Periorbital tumours & 26 & $34.7 \%$ \\
\hline Periorbital pigmentation & 18 & $24 \%$ \\
\hline Periorbital dermatitis & 18 & $24 \%$ \\
\hline Periorbital infections & 7 & $9.3 \%$ \\
\hline Miscellaneous & 6 & $8 \%$ \\
\hline
\end{tabular}

Out of 75 patients, 26 patients presented with periorbital tumours. The most common periorbital tumour seen was skin tags observed in 12 patients (16\%), followed closely by seborrheic keratosis in 10 patients, followed by neurofibroma in 2 patients and syringoma and angiofibroma was seen in 1 patient each. The distribution of periorbital tumours in our study is provided in table 2. (Fig. 1,2)

Table 2: Number of cases with periorbital tumours

\begin{tabular}{|l|c|}
\hline Periorbital tumours & No. of cases \\
\hline Seborrhoeic keratosis & 10 \\
\hline Skin tags & 12 \\
\hline Neurofibroma & 2 \\
\hline Syringoma & 1 \\
\hline Angiofibroma & 1 \\
\hline
\end{tabular}

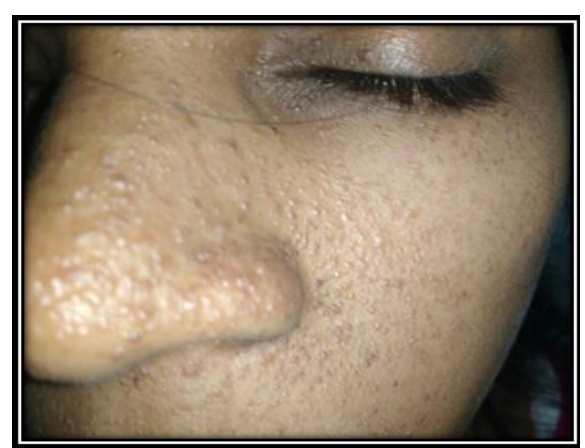

Fig. 1: Clinical picture showing angiofibroma

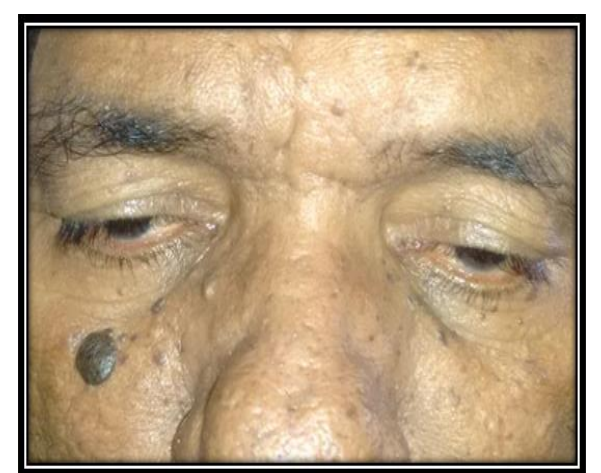

Fig. 2: Clinical picture showing seborrheic keratosis

Out of 75 patients, 18 patients presented with periorbital pigmentation. Periorbital pigmentation was the second most common periorbital dermatoses observed. Hyperpigmentation was more common than hypopigmentation or depigmentation. Out of 18 patients, most commonly encountered condition was melisma. Melasma was seen in 8 patients, next was periocular melanosis in 6 patients followed by pityriasis alba in 3 patients and vitiligo in 1 patient as shown in Table 3.

Table 3: Number of cases showing periorbital pigmentation

\begin{tabular}{|l|l|}
\hline Periorbital pigmentation & No. of cases \\
\hline Melasma & 8 \\
\hline Periocular Melanosis & 6 \\
\hline Pityriasis alba & 3 \\
\hline Vitiligo & 1 \\
\hline
\end{tabular}

Dermatitis in the periorbital region was also another commonest dermatoses seen in our study. 18 patients out of 75 reported with periorbital dermatitis. Of which 8 patients had allergic contact dermatitis to various antigens, followed by irritant contact dermatitis in 7 patients. Atopic dermatitis and seborrheic dermatitis were seen in 2 and 1 patient respectively as shown in table 4.

Table 4: Number of cases showing periorbital dermatitis

\begin{tabular}{|l|c|}
\hline Periorbital dermatitis & No. of Cases \\
\hline Allergic contact dermatitis & 8 \\
\hline Irritant contact dermatitis & 7 \\
\hline Atopic dermatitis & 2 \\
\hline Seborrhoeic dermatitis & 1 \\
\hline
\end{tabular}

7 out of 75 patients $(9.3 \%)$ presented to OPD with various periorbital infections, of which 3 patients had periorbital warts, 2 patients had tinea versicolor, and 1 patient with herpes zoster ophthalmicus (Fig. 3)and 1 patient with molluscum contagiosum were encountered. Miscellaneous conditions like acne, senile comedones, vesicobullous disorders,c onnective tissue disorders were seen in total 6 patients $(8 \%)$. 


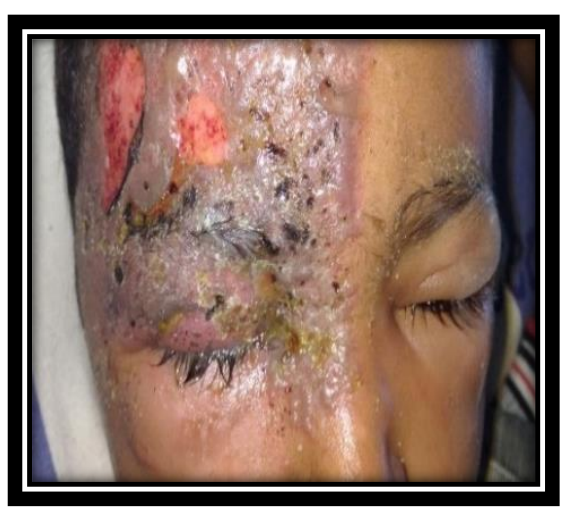

Out of all the dermatoses, skin tags $(16 \%)$ were the commonest dermatoses followed by seborrheic keratoses (13.3\%), then Allergic contact dermatitis (ACD) and melasma (10.7\%), Irritant contact dermatitis (9.3\%), periocular melanosis and miscellaneous causes constituted each upto $8 \%$ of the patients, followed by periorbital warts and pityriasis alba (4\% each), Atopic dermatitis, Neurofibroma, Pityriasis versicolor $(2.7 \%$ each), and syringoma, angiofibroma, vitiligo, seborrheic dermatitis, molluscum contagiosum and herpes zoster ophthalmicus patients were $1.33 \%$ each as shown in Graph 1.

Fig. 3: Clinical picture showing herpes zoster ophthalmicus

\section{Graph 1: Bar diagram showing spectrum of periorbital dermatoses}

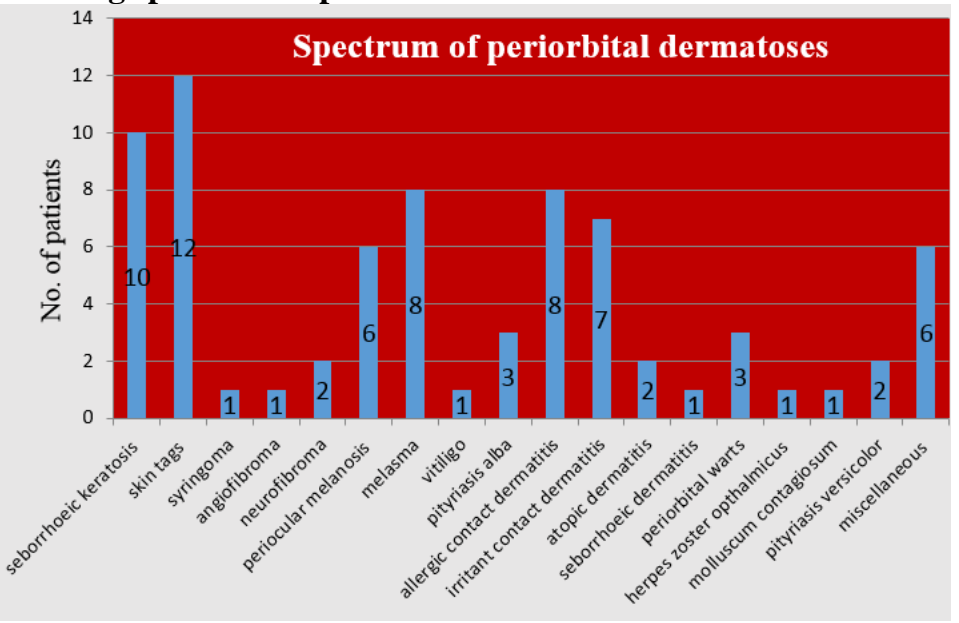

\section{Discussion}

Periorbital region is predisposed to various dermatoses and all types of skin disorders may affect the area surrounding the eye. As the periorbital area is easily visible, any changes in this area can lead to intense psychological distress and may significantly affect the quality of life of the patient. ${ }^{1}$

The common periorbital disorders encountered in descending order in this present study includes skin tags, seborrheic keratoses, allergic contact dermatitis, melasma, irritant contact dermatitis, periocular melanosis, acne, pityriasis alba, periorbital warts, tinea versicolor, neurofibroma, angiofibroma, molluscum contagiosum, syringoma, herpes zoster ophthalmicus, vesiculobullous disorders, vitiligo and connective tissue disorders.

Amongst the periorbital tumours, seborrhoeic keratoses (SK) is the most common benign epidermal tumors made up of of epidermal keratinocytes. ${ }^{4}$ Commonly seen in middle-aged individuals and most frequently occuring on face and upper trunk but may occur at any site. ${ }^{5}$

Seborrhoeic keratosis clinically appear as stuck on, verrucous papule with psuedohorn cysts.
Tan or dark brown in color is due to increase in number of melanocytes.

Multiple lesions are also seen distributed in Christmas tree pattern or in Blaschko's lines. ${ }^{6}$

Skin tags present as multiple, soft, skin colored pedunculated papules and few may have a long stalk. On an average may vary about $2 \mathrm{~mm}$ in diameter. They are firm to soft in consistency and inelastic. The most commonly affected site is the neck, where they may be mixed with typical small, sessile, seborrhoeic keratosis. In extensive presentation, they may extend on to the face, eyelids or down to the back, chest, axilla and groin. An association with colonic polyps, diabetes, and acromegaly has been suggested..$^{7-9}$

Periorbital pigmentation was the second common dermatoses seen in our study. Periorbital hyperpigmentation $(\mathrm{POH})$ presents with a dark area surrounding the eyelids, commonly known as "Dark circle" is an ill-defined entity and is of common aesthetic concern. POM can be due to four major causes: Dermal melanin deposition, post inflammatory hyperpigmentation from atopic or contact allergic 
dermatitis, shadowing from lax skin and infraorbital swelling. ${ }^{10,11}$

Among Indians Melasma is most common pigmentary disorder which is most commonly seen on the face, less frequently on the neck, and rarely on the forearms. $^{12}$ Incidence is common amongst females when compared to male which comprises about $10 \%$ of cases. $^{13}$

Periorbital dermatitis is often of multifactorial origin. It may be acute or chronic. ${ }^{14}$ As periorbtal dermatitis are prominent on the face they are quite distressing for the patient. ${ }^{15}$ The disorder does not resolve quickly and patients may need to undergo repeated therapies with topical corticosteroids, which tend to fail to achieve a long lasting improvement and can also involve steroid-induced side effects (skin atrophy, telangiectasias, rebound phenomenon). ${ }^{16}$

Irritant contact dermatitis is a non-immunologic local inflammatory reaction characterized by redness, swelling, or corrosion following single or repeated applications of an irritant to the skin. Irritant contact dermatitis is much less common at periocular sites than on the hands where various irritant exposures are possible. ${ }^{17,18}$ Dust, fumes, and mechanical factors can have an irritating effect on facial skin and should be considered as potential triggers in patients with periocular dermatitis.

Common perorbital infections include verruca vulgaris, herpes zoster opthalmicus, molluscum contagiosum, pyoderma, leprosy, tinea versicolor.

A study done on periorbital dermatoses by Indradevi et al, reported the commonest periorbital dermatoses which was periorbital tumours that constituted $26.3 \%$ followed by periorbital pigmentation $19.3 \%$, infections $13 \% .^{2}$

In a study done by Besra $\mathrm{L}$ et al. the most common dermatological conditions in periorbital region were benign and malignant skin tumors observed in 63 $(25.2 \%)$ cases, followed by the disorders of pigmentation in $51(20.4 \%)$ and eczema in 44 cases $(17.6 \%)$, infections in $33(13.2 \%)$ cases and nevoid conditions in $26(10.4 \%)$ cases. ${ }^{18}$

In a study done by Peralejo B, Beltrani $\mathrm{V}$ of 80 patients with benign eyelid and conjunctival tumours, the most frequent tumours was intradermal nevus (44.6\%), Seborrhoeic keratosis $(16.1 \%)$, and compound nevus $(10.7 \%)$ in eyelid tumours. ${ }^{19}$

A study done by Nalini $\mathrm{P}$ et al reported, periorbital tumours to be the commonest $(41.8 \%)$, followed by pigmentation $(19.1 \%)$, followed by infection and periorbital dermatitis $5.5 \%$ each. ${ }^{20}$
Table 5

\begin{tabular}{|l|c|c|c|c|}
\hline $\begin{array}{l}\text { Periorbital } \\
\text { dermatoses }\end{array}$ & $\begin{array}{c}\text { Our } \\
\text { study }\end{array}$ & $\begin{array}{c}\text { Indradevi } \\
\text { et al }\end{array}$ & $\begin{array}{c}\text { Nalini } \\
\text { P et al }\end{array}$ & $\begin{array}{c}\text { Besra } \\
\text { L et al }\end{array}$ \\
\hline Tumours & $34.7 \%$ & $26.3 \%$ & $41.8 \%$ & $25.2 \%$ \\
\hline Pigmentation & $24 \%$ & $19.3 \%$ & $19.1 \%$ & $20.4 \%$ \\
\hline Infection & $9.3 \%$ & $13 \%$ & $5.5 \%$ & $13.2 \%$ \\
\hline dermatitis & $24 \%$ & $17.3 \%$ & $5.5 \%$ & $17.6 \%$ \\
\hline
\end{tabular}

In our study, Out of the 75 patients, 26 patients $(34.7 \%)$ had periorbital tumours. The next most common periorbital dermatoses are pigmentary disorders and periorbital dermatitis seen in 18 patients (24\%) each, followed by periorbital infections seen in 7 patients $(9.3 \%)$ and 6 patients $(8 \%)$ had miscellaneous periorbital dermatoses.

In our study peri orbital tumours were the commonest $(34.7 \%)$, amongst which skintags were the most commonly observed (16\%) followed by seborrheic keratosis (13.3\%). Pigmentation (24\%) was the second most common periorbital dermatoses observed with melasma being the commonest among them $(10.7 \%)$ These results are similar to the studies done by Nalini $\mathrm{P}$ et al, Indradevi et al, Besra et al. ${ }^{20,2,18}$

In our study, $9.3 \%$ of the patients presented with periorbital infections and periorbital dermatitis was seen in $24 \%$ of the patients which was comparable to the studies done by Indradevi et al, Besra et al. ${ }^{2,18}$

\section{Conclusion}

Certain periorbital dermatoses are heralding features of underlying systemic disease, so it helps in early diagnosis and treatment of underlying condition. In our study periorbital tumours are the commonest dermatoses seen. The most common periorbital tumors observed in our study were skin tags. The results in our study correlated with other available literature on periorbital dermatoses. However, the sample size we had considered was small and more studies with larger sample size need to be undertaken.

Funding: No funding sources.

Conflict of interest: None declared.

\section{References}

1. Rebora A. Periorbital lesions. Clin Dermatol 2011;29:151-6.

2. Indradevi R, Oudeacoumar P, Medasani V, Rao C. Spectrum of periorbital dermatoses in a tertiary care centre in Puducherry. Int J Res Dermatol 2017;3:489-94.

3. Chang P, Moreno-Coutiño G. Periocular dermatoses. Int J Women's Dermatol 2017;3(4):206-18. doi:10.1016/j.ijwd.2017.08.001.

4. Mackie RM, Quinn AG. Non-melanoma skin cancer and other epidermal skin tumors. In: Burns T, Breathnach S, Cox N, Griffiths C, editors. Rook's Textbook of Dermatology. 7 th ed. Oxford: Blackwell Publishing; 2004. p. 36.1-36.50.

5. Basler RGW, Taylor WB, Peacor DR. Post-acne osteoma. Arch Dermatol 1974;110:113-4. 
6. Li YH et al: Detection of epidermodysplasia verruciformis-associated human papillomavirus DNA in nongenital seborrheic keratosis. Br J Dermatol 2004;151:1060.

7. Chobanian SJ. Skin tags and colonic polyps: a gastroenterologist's perspective. J Am Acad Dermatol 1987;16:407-9.

8. Margolis J, Margolis LS. Skin tags: a frequent sign of diabetes mellitus. N Engl J Med 1976;294:1184.

9. Lawrence JH, Tobias CA, Linfoot JA, et al. Successful treatment of cromegaly: metabolic and clinical studies in 145 patients. J Clin Endocrinol Metab 1970;31:180-98.

10. Malakar S, Lahiri K, Banerjee U, Mondal S, Sarangi S. Periorbital melanosis is an extension of pigmentary demarcation line-F on face. Indian J Dermatol Venereol Leprol 2007;73:323-5.

11. Roh MR, Chung KY. Infraorbital dark circles: Definition, causes, and treatment options. Dermatol Surg 2009;35:1163-71.

12. Pasricha JS, Khaitan BK, Dash S. Pigmentary disorders in India. Dermatol Clin 2007;25:343-522.

13. Sivayathorn A. Melasma in Orientals. Clin Drug Investig 1995;10(Suppl 2):24-40.

14. Feser A, Plaza T, Vogelgsang L, Mahler V. Periorbital dermatitis -a recalcitrant disease: Causes and differential diagnoses. Br J Dermatol 2008;159:858-63.
15. Davies E, Patel C, Salek MS, Finlay AY. Does ad hoc quality-of-life discussion in inflammatory skin disease consultations reflect standardized patient-reported outcomes. Clin Exp Dermatol 2008;33:16-21.

16. Hayreh SS. Orbital vascular anatomy. Eye (Lond) 2006;20(10):1130-44.

17. Dickel H, Kuss O, Schmidt A, Kretz J, Diepgen TL. Importance of irritant contact dermatitis in occupational skin disease. Am J Clin Dermatol 2002;3:283- 9.

18. Besra L, Jaisankar T J, Thappa DM, Malathi M, Kumari R. Spectum of periorbital dermatoses in south Indian population. Indian J Dermatol Venereol Leprol 2013;79:399-407.

19. B, Beltrani V, Bielory L. Dermatologic and allergic conditions of the eyelid. Immunol Allergy Clin North Am 2008;28:137-68.

20. Nalini P, Manickam N, Gopalan K, Muthusamy K. A study on spectrum of periorbital dermatoses in a tertiary centre. Int J Res Dermatol 2018;4:149-56.

How to cite this article: Shetty M., Sowmya. A cross sectional study of periorbital dermatoses in a tertiary care hospital in South India. Indian J Clin Exp Dermatol 2018;4(4):297-301 